Revue

Revue de l'histoire des religions

de Ihistoire des religions

3 | 2017

Varia

\title{
Thomas RÖMER, Les 100 mots de la Bible
}

Paris, PUF (« Que sais-je ?», 4057), 2016

\section{Christophe Lemardelé}

\section{OpenEdition}

\section{Journals}

Édition électronique

URL : http://journals.openedition.org/rhr/8762

DOI : 10.4000/rhr.8762

ISSN : 2105-2573

\section{Éditeur}

Armand Colin

\section{Édition imprimée}

Date de publication : 1 septembre 2017

Pagination : 525-527

ISBN : 978-2-200-93127-8

ISSN : 0035-1423

Référence électronique

Christophe Lemardelé, "Thomas Römer, Les 100 mots de la Bible», Revue de l'histoire des religions [En ligne], 3 | 2017, mis en ligne le 01 septembre 2017, consulté le 07 janvier 2021. URL : http:// journals.openedition.org/rhr/8762; DOI : https://doi.org/10.4000/rhr.8762

Ce document a été généré automatiquement le 7 janvier 2021

Tous droits réservés 


\title{
Thomas RöMER, Les 100 mots de la Bible
}

Paris, PUF (« Que sais-je ? », 4057), 2016

\author{
Christophe Lemardelé
}

\section{RÉFÉRENCE}

Thomas RöMER, Les 100 mots de la Bible, Paris, PUF (« Que sais-je ?», 4057), 2016, $18 \mathrm{~cm}$, 127 p., $9 €$, ISBN 978-2-13-0735515-1.

1 Assurément, Thomas Römer, professeur au Collège de France, était le mieux placé pour donner des entrées simples à l'étudiant en manque de culture religieuse pour concrétiser quelques connaissances sur la Bible hébraïque, c'est-à-dire l'Ancien Testament. Puisque ce petit ouvrage n'est pas à lire de manière linéaire - ce que l'on ne devrait d'ailleurs pas faire avec la Bible même -, le lecteur pourra commencer par la dernière entrée : "YHWH ». Ainsi pourra-t-il découvrir que le nom divin - le fameux tétragramme - n'est pas si imprononçable que cela - Yahou est bien plus probable que le désormais désuet Jehovah, et même que le conventionnel Yahvé... -, bien que l'on ne sache toujours pas véritablement pourquoi il y eut un interdit sur ce nom même. Il y a l'idée d'un dieu caché qui devient tous les dieux : Élohim/ «Dieu », un pluriel traduisant paradoxalement le "Monothéisme »... Et c'est finalement sa relation exclusive avec Israël, par le biais de l'«Alliance» qui fait de cette conception religieuse une conception atypique par rapport à des systèmes polythéistes. Le rituel même de l'alliance, c'est-à-dire du serment, est parfaitement proche-oriental (p. 14), mais le dieu qui l'impose et s'y soumet implique à la fois une relation de grande proximité et la nécessité de se soustraire à la vue humaine, comme dans le "Jardin» d'Éden. Il faut encore ajouter au sujet de cette divinité son origine géographique spécifique, ni israélite ni véritablement sinaïtique car «des textes poétiques anciens (...), qui décrivent la venue de Yhwh du Sinaï, mettent cet endroit en parallèle avec Séïr ou Édom, c'est-à-dire avec une région au sud-est de Juda dans la partie sud de la Jordanie 
actuelle » (p.119). Et il est vraisemblable de penser que ce dieu fut transporté jusqu'en Israël dans un sanctuaire mobile qui devait renfermer sa statuette - pour notre part, nous penserions plutôt à un bétyle, c'est-à-dire à une pierre non sculptée, ni anthropomorphe ni zoomorphe - bien avant que ce sanctuaire ne devînt dans les textes l'« Arche de l'alliance » renfermant les tables de la Loi (p. 20-21).

2 Autre terme énigmatique : « Hébreu ». De nos jours encore, l'histoire des Hébreux reste dans l'imaginaire collectif alors que ce " gentilice délibérément archaïsant» (p.65) est relativement peu présent dans les textes bibliques. Il faut lui préférer « Israël », même si ce terme a pris des significations distinctes selon les époques (et jusqu'à nos jours), puis «Samaritains » de Samarie et Judéens de «Jérusalem », cité prébiblique dont le nom se réfère à une divinité céleste ancienne dénommée Shalem. De même, l'organisation d'Israël en douze "Tribus » est également une construction tardive, développée au point qu'il ait pu y avoir « l'espoir de la restauration d'un Israël tribal » (p. 124). Le peuple d'Israël a-t-il connu un «Exode » ? L'A. en doute même s'il considère qu'il s'agit d'une tradition ancienne. En revanche, l'« Exil» fut bien une réalité qui marqua de manière décisive les textes bibliques. Par exemple, la question de la terre promise, de la possession du " Pays ", se comprend d'autant mieux après cette période où les élites de Juda furent exilées au début $d u \mathrm{VI}^{\mathrm{e}}$ siècle avant l'ère chrétienne (p. 98-99). Cependant, ce qui est avéré historiquement et qui est le plus ancien concernant « Israël » se trouve sur la stèle égyptienne du pharaon Mérenptah à la toute fin du XIII ${ }^{\mathrm{e}}$ siècle. Sur cette stèle de victoire en effet se trouve la mention d'une entité politique vraisemblablement tribale puisque non liée à une ville, dont le nom théophore indique la vénération du grand dieu ouest-sémitique El et non encore Yhwh (p. 71). Le grand récit biblique doit être déconstruit pour en chercher les éléments fondés historiquement, il ne s'agit aucunement de conclure à l'affabulation générale. La Bible hébraïque n'est pas un récit historique mais les textes qui la composent sont bien des documents de cet ordre, même si les éléments historiques avérés ont été interprétés à l'aune d'une idéologie spécifique et particulièrement remaniés dans des trames littéraires complexes.

3 Le plus important dans ce dictionnaire biblique de poche est de situer nombre de notions dans un contexte historique et culturel proche-oriental et mésopotamien. L'A. le fait presque systématiquement, qu'il s'agisse naturellement d'emprunts mythologiques liés à la «Création » et au " Déluge » ou bien d'aspects ouest-sémitiques secondaires tel le nom commun Abram avant qu'il ne devînt «Abraham »-il n'en est pas de même pour Moïse dont le nom est égyptien (p. 90) -, ou qu'il s'agisse encore de grands événements. Par exemple, l'exil de l'élite hiérosolymitaine à Babylone est mis en regard de la pratique de la déportation systématisée par l'empire néo-assyrien et cet exil a pu se décliner en trois vagues successives : 597, 587 et peut-être 582 avant l'ère chrétienne (p. 55). L'importance de cette émigration forcée, dont fit partie le prêtre devenu prophète Ézéchiel dès 597, peut sans doute expliquer pourquoi le judaïsme en devenir fut tant influencé par des déportés (la Golah) qui se pensèrent comme le seul Israël légitime (p. 58). Thomas Römer est aussi le mieux à même de proposer quelques connaissances simples au sujet de la rédaction des textes bibliques dont il est un grand spécialiste. Les entrées "Pentateuque", "Deutéronome", "Décalogue » sont évidemment parmi les plus importantes, surtout lorsqu'il s'agit de préciser que le dernier livre de la Torah a été écrit sur le modèle d'un traité de vassalité assyrien du VII siècle (p. 42). Enfin, concernant la notion de «Canon » appliquée à ces textes dès le 
IV siècle avant notre ère, il importe de souligner un processus sur le long terme, de la fixation définitive d'un livre, voire d'un corpus délimité, à la sacralisation des textes hébraïques par les rabbins au II $^{\mathrm{e}}$ siècle de notre ère (p. 28-29), cela d'autant plus avec la grande variété manuscrite des livres bibliques et du fait de la multiplicité d'autres textes depuis la découverte des rouleaux de "Qumran" datant du II $^{\mathrm{e}}$ et du I ${ }^{\mathrm{er}}$ siècle avant notre ère. Qu'il s'agisse, en amont, de contextes complexes et difficiles à restituer, ou, en aval, d'une richesse textuelle presque impossible à maitriser "chaque recopiage était aussi l'occasion d'ajouter ou de supprimer des choses, ou encore d'apporter des modifications » (p. 107-108) -, la Bible ne peut être comprise sans l'aide d'un petit « grimoire » tel que celui-ci.

\section{AUTEURS}

\section{CHRISTOPHE LEMARDELÉ}

UMR 8167 Orient \& Méditerranée. 